\title{
MESA 2: LA UNIVERSIDAD DE CHILE Y EL SISTEMA DE EDUCACIÓN SUPERIOR
}

Andrea Valdivia: Doctora en Educación y Académica del Instituto de la Comunicación e Imagen.

María Olivia Mönckeberg: Premio Nacional de Periodismo y Directora del ICEI.

Manuel Antonio Garretón: Premio Nacional de Humanidades y

Ciencias Sociales y Profesor titular de la Universidad de Chile.

Jesús Redondo: Doctor de Filosofía y Ciencias de la Educación y

Director del Observatorio Chileno de Politicas Educativas. 


\section{MESA 2: "LA UNIVERSIDAD DE CHILE Y EL SISTEMA DE EDUCACIÓN SUPERIOR"}

Andrea Valdivia: En un primer lugar me gustaría que pudiéramos pensar y discutir acerca del estado actual del sistema educacional: ¿Qué características tiene el sistema de educación superior? ¿Cómo es su estructura? ¿Cómo son los actores que participan en él? ¿Cómo ha sido la orgánica que ha ocurrido en los últimos tiempos y que desencadena, justamente, en el estado actual? Damos la palabra, en primer lugar, a María Olivia Mönckeberg.

María Olivia Mönckeberg ${ }^{31}$ : Buenos días. Preparé una presentación en la que me apoyaré porque hay algunos números y figuras que quisiera ilustrar. Para partir, vamos a recordar por qué estamos donde estamos: la situación actual es consecuencia de una dictadura, su intervención de las universidades y la aplicación de un modelo.

Tras el Golpe Militar de 1973, las ocho universidades existentes -dos estatales, la Universidad de Chile y la Universidad Técnica del Estado y seis particulares tradicionales- fueron intervenidas.

A fines de los años ochenta y comienzos de 1981 se promulgaron una serie de decretos conocidos como Ley General de las Universidades. Estos decretos debilitaban a la Universidad de Chile y uno de ellos -el número 1- autorizó la fundación de universidades privadas como corporaciones "sin fines de lucro".

Un elemento clave de la nueva política fue el despojo de las sedes regionales de la Universidad de Chile. Esta casa de estudios, la más antigua y principal del país, perdió en esa ocasión el Instituto Pedagógico y algunas otras carreras que se daban en Santiago.

Asimismo, el Gobierno cambió el sistema de financiamiento. Instauró el Aporte Fiscal Directo, así como el Aporte Fiscal Indirecto (AFI) y los créditos a los estudiantes para el pago de los aranceles, pues antes la educación era gratuita o se pagaba muy poco.

31 Al final de este apartado se encuentran las láminas expuestas por la Profesora María Olivia Mönckeberg, que permiten comprender mejor la transcripción de su intervención en el coloquio. 
A través de otra disposición se dio la posibilidad de que surgieran entidades nuevas, como los Institutos Profesionales y los Centros de Formación Técnica, que nunca habían existido en la historia del país. Y a estos se les permitió tener lucro.

El Gobierno implantó también poco después la política de los fondos concursables Fondecyt para la investigación orientados a los académicos, en lugar de dar financiamiento para que las instituciones investigaran.

Es interesante recordar que ese año, 1981, fue el que empezó a regir la Constitución de 1980 y partieron justamente como forma de instauración de un modelo, que hoy conocemos como neoliberal, las Asociaciones de Fondos de Pensiones Privadas (AFP), las Instituciones de Salud Privada (Isapres) y se empezó a avanzar en la municipalización de la educación básica y media. Además, se fomentaron las subvenciones del Estado a colegios privados, los que crecieron después en forma notable: son los que conocemos hoy como particulares subvencionados.

En los primeros años ochenta solamente surgieron tres universidades privadas, que fueron las pioneras: Gabriela Mistral, Diego Portales y Universidad Central. Todas ellas nacieron con permiso del Ministerio del Interior y del de Educación, como se había establecido. Pero la crisis económica que se hizo evidente en 1982 y las protestas sociales que partieron en 1983 provocaron incertidumbre en los grupos económicos e ideológicos que o no pudieron o no se interesaron en levantar universidades privadas, por lo que sólo se generaron esas tres de la primera ola. Ya hacia el término de la dictadura, cuando Pinochet tenía que entregar el poder y cuando quienes lo acompañaban veían que no iban a poder seguir dirigiendo las universidades tradicionales que dejarían de estar intervenidas, se crearon las universidades privadas que hoy conocemos como "universidades privadas nuevas" o post 81. En su mayoría, surgieron a finales del 89 y comienzos del año 90 . La mayor parte fue formada por personas que participaron de la dictadura o apoyaron la dictadura y hoy se vinculan a los partidos de derecha: UDI y Renovación Nacional.

Como corolario, el último día del régimen de Pinochet, antes de empezar la transición, dictó la Ley Constitucional de Enseñanza, la LOCE, firmada por él y por el entonces ministro de Educación René Salamé, que fue tan combatida por los pingüinos en 2006 y por los estudiantes universitarios.

En estos 24 años la educación superior en Chile ha cambiado radicalmente. Del total de 622.736 alumnos matriculados en 2013 en universidades, 335.136 eran alumnos de las privadas nacidas después de 1981 y solo 161.446 mil eran estudiantes de universidades estatales. Y 126.154 estudiantes de tradicionales no estatales.

Por lo tanto, un 53,8 por ciento de los universitarios está en privadas post 81 , y sólo el 26 por ciento estudia en universidades estatales; y un 20 por ciento en las otras universidades del Consejo de Rectores $(\mathrm{CRUCH})$, que son las tradicionales no estatales. 
Un dato significativo relacionado con esa cantidad de estudiantes reclutados por las universidades privadas: en 2013 estas entidades recibieron más de mil quinientos millones de dólares por ingresos de pregrado.

Para completar el cuadro, hay que considerar que, además, están los alumnos de los institutos profesionales, que alcanzaban a 317.929 alumnos, y los de centros de formación técnica, que sumaban 135.003 estudiantes en 2013; es decir, 452.932 alumnos asistían a esos establecimientos.

En total, el sistema de educación superior en Chile estaba compuesto por más de un millón 75 mil alumnos.

En ese cuadro, los alumnos de las universidades públicas -léase estatales- sólo representan el 15 por ciento de todo el sistema de educación superior.

Eso hace que las presiones por evitar los cambios y el fortalecimiento de la educación superior pública sean y vayan a seguir siendo más fuertes que lo que hemos visto hasta ahora. Como señalaba el Rector Ennio Vivaldi al comenzar su exposición en este Simposio, a la Universidad de Chile la trataron de destruir. No la destruyeron, pero, a cambio, se fortaleció este conjunto de universidades y entidades privadas que han obtenido durante los últimos años ganancias exageradas y fraudulentas. Esto representa una situación de deshonestidad escandalosa, ya que originalmente se estableció en el Decreto Ley No 1 de 1981 y en la LOCE de 1990 que las universidades no podían lucrar. Y lo han hecho a caudales en estos años, usando diferentes fórmulas y artilugios.

A continuación, pueden observar algunas láminas que nos muestran los ingresos reales de las universidades según estructuras de la propiedad. Estos gráficos, preparados para esta exposición por sociólogos ex alumnos de la Universidad de Chile, fueron elaborados sobre la base de estadísticas del Ministerio de Educación 2013.

Si apreciamos lo que implican los ingresos reales por pregrado de las universidades en 2013, el gráfico ilustra lo que ocurre en el sistema, con el avance constante de los ingresos a las privadas nuevas -marcadas en verde- y lo que representan en la actualidad.

Detrás de estos números y estas imágenes está la situación del sistema universitario, que en realidad más que un sistema me parece un caos. Una realidad que hemos estado viendo con los escándalos que explotaron en torno a la Comisión de Acreditación (CNA) y a la Universidad del Mar, así como los problemas que están enfrentando otras universidades, como la ARCIS en estos días, o la seria situación que vive la Universidad de Las Américas y, en general, el grupo Laureate.

Lo anterior implica que hay 12 universidades que están en este momento -agosto de 2014- investigadas por lucro por el Ministerio Público: Andrés Bello, Las Américas, Viña del Mar, del Desarrollo, San Sebastián, Santo Tomás, Autónoma, 
Central, del Mar, Uniacc, SEK, Pedro de Valdivia. Además, la Universidad del Mar, Pedro de Valdivia, Uniacc y SEK son investigadas por el caso CNA.

Hay que tener presente lo que sucede en torno a esas universidades al momento de pensar en mayores aportes del Estado. Estos pueden ir a aumentar el negocio a costa del propio Estado y de los estudiantes y sus familias. Aunque están siendo investigadas por lucro por la Fiscalía de Delitos de Alta Complejidad, aún no ha podido configurarse el delito mismo de lucro. Porque si bien la ley prohíbe lucrar, no se había determinado el delito de lucro en la legislación y, por lo tanto, no está constituida la figura penal. Esa es una de las cuestiones que tendría que revisar y legislar el Parlamento, porque parece necesario penalizar el lucro para lograr evitarlo.

Entretanto, algunas de estas universidades probablemente caigan en delitos tributarios, como los que se han estado viendo en el caso de las del Grupo Laureate, que es el más poderoso de los que opera en la educación superior.

La impresión que uno tiene al analizar el asunto es que esto ha sido un tremendo negocio. Y se observa que la mayoría de las universidades privadas, entre estas las que más han crecido o las que más influyen, están vinculadas a grupos económicos y en muchos casos mantienen redes políticas de apoyo. Algunos personajes que están detrás de su propiedad o en sus directivas son muy fuertes y con mucha influencia. Y eso se advertirá más cuando empiece a plantearse la reforma en la educación superior. Además de la Iglesia Católica -relacionada directamente con muchas universidades tradicionales y nuevas-, ya se han visto algunos actores que quieren más apoyo del Estado y escasa regulación. Sostienen que todas las universidades son iguales, sin importar la propiedad ni la trayectoria. Y aparecerán, sin duda, otros actores que levantarán su voz. Detrás de las corporaciones universitarias hay grupos e intereses importantes, tanto económicos como ideológicos.

Según la Contraloría General de la República en el año 2013, de acuerdo con los datos de la ejecución presupuestaria, se distribuyó un total de M\$1.238.996.037 a educación superior.

Un 71,5 por ciento fue asignado a estudiantes, a través de créditos y becas, y sólo un 28,5 por ciento a las instituciones.

El financiamiento fiscal a la educación superior hasta ahora está orientado mayoritariamente hacia los alumnos, es decir, hacia la demanda, a través de la aplicación de un sistema de vouchers que ha favorecido a las universidades privadas masivas.

Así, los aportes recibidos por la Universidad Andrés Bello (UNAB), San Sebastián, Santo Tomás, Autónoma; los institutos DUOC, AIEP e IP de Chile, y los CFT Inacap y Santo Tomás fueron superiores a ocho de las 16 universidades estales. 
El 34,1 por ciento de este financiamiento hacia los estudiantes se efectuó en 2013 a través del Crédito con Aval del Estado (CAE). Y el CAE ha seguido creciendo. En 2013 aumentó en 10,5 por ciento respecto a 2012.

La gran parte de este CAE se entregó a las universidades privadas (209 mil 495.421 millones de pesos), lo que representa un 69,3 por ciento de todo el CAE. Es este financiamiento el que ha gatillado aumentos considerables de matrícula desde 2006 en estas entidades. En 2013 se distribuyó en 27 instituciones, entre las que destacan las universidades San Sebastián, Santo Tomás, Andrés Bello, Autónoma y Las Américas.

A cada una de ellas se le destinó un monto mayor al total asignado a las 16 universidades estatales.

Entonces, cambiar este estado de cosas, incrementar esa proporción de la educación pública y fortalecer a las universidades estatales aparece hoy como un mandato que, desde la Universidad de Chile, es una de las partes donde fundamentalmente tenemos que empujarlo. Pero no es tarea fácil.

Para tener una idea de lo que está en juego y quiénes están en el juego podemos ilustrar con algunas imágenes de este poder y sus influencias.

El grupo Laureate (ex Sylvan International), bajo el control desde 2007 del fondo de inversiones estadounidense KKB (Kohlberg, Kravis, Roberts), inauguró las compraventas de "carteras de alumnos" al adquirir Las Américas y el Instituto Profesional Campus, en 2003. Este grupo extranjero, que cuenta con directivos chilenos en su gestión, adquirió después la "cartera" de la Universidad Andrés Bello en 2004 y el Instituto Profesional AIEP.

Hoy es dueño de las dos universidades privadas con más alumnos y uno de los tres mayores institutos. Las Américas -con 34.455 alumnos en 2013- y Andrés Bello -con 45.233- suman casi 80 mil estudiantes: más del doble de la U. de Chile (37.173). En 2009 Laureate compró además la U. de Viña del Mar (7.610 alumnos) y la Escuela Moderna de Música que transformó en IP. Laureate, en conjunto, reúne a más de 120 mil estudiantes, por lo que es el más numeroso y el que más CAE se lleva.

Hasta abril de 2014 presidió el directorio Herman Chadwick Piñera, ex presidente del Consejo Nacional de Televisión (CNTV), primo hermano del ex Presidente Sebastián Piñera y hermano de su Ministro del Interior Andrés Chadwick. Hasta esa fecha fue también miembro de la junta directiva el ex Ministro Genaro Arriagada y el empresario Fernán Gazmuri Plaza, presidente de la Asociación Chilena de Seguridad.

Un hombre decisivo del grupo es Jorge Selume Zaror, el último director de Presupuesto de Pinochet y mano derecha durante años de Alvaro Saieh, con quien 
fue socio también en la Universidad Andrés Bello. Otro director de Las Américas desde hace años es el periodista y asesor de la UDI Manfredo Mayol.

En la presidencia de Las Américas, tras el alejamiento de Chadwick quedó el economista UDI José Pedro Undurraga, anterior rector de esta universidad y ex rector de Inacap.

El grupo se ha preocupado también de reclutar figuras que estuvieron ligadas a la Concertación, como es el caso de la ex jefa de Educación Superior Pilar Armanet, actualmente rectora de Las Américas y antes vicerrectora. Y la decana de Educación es la ex subsecretaria Pilar Romaguera. Participa también en el grupo el ex jefe de Educación Superior Julio Castro, que fue rector de la Universidad de Viña del Mar.

En la Universidad Andrés Bello el presidente es Juan Antonio Guzmán Molinare, el ex Ministro de Pinochet a mediados de los 80, bajo cuyo mandato fue instalado en la Universidad de Chile el polémico rector delegado José Luis Federici en 1986. Guzmán Molinare preside también la Clínica Indisa y está relacionado con la Inmobiliaria Andrés Bello, que se vincula, a su vez, con la Universidad San Sebastián. También Guzmán Molinare preside la Empresa de Comunicaciones Extend e integra el directorio de Soquimich.

Guzmán Molinare es cuñado del ex Subsecretario de Hacienda y ex presidente de la UDI, Julio Dittborn. Está casado con Paulina Dittborn Cordua, quien a su vez era vicepresidenta del Consejo Superior de Educación y fue hasta el 2011 Prorrectora de la Universidad de Las Américas. Actualmente Paulina Dittborn es Decana de Educación de la Universidad Santo Tomás y Directora Académica de los colegios Santo Tomás. Esta pareja fue clave en el control de Inacap y de la Universidad Tecnológica, que es otra de las que recibe importantes recursos del Estado.

Más figuras conocidas: Carlos Larraín Peña, el expresidente de Renovación Nacional, dijo en una entrevista que tenía interés en una universidad. Es posible que se haya referido a la Santo Tomás, porque su cuñado, Juan Hurtado Vicuña, líder de uno de los principales grupos económicos actuales, "compró" (a pesar de que no se podía comprar y vender una universidad), el año 2009, junto al Fondo de Inversiones Linzor Capital, la mayoría de las acciones de la Corporación Santo Tomás, entidad que había sido creada por Gerardo Rocha. La Corporación incluye a la Universidad Santo Tomás, al Instituto Profesional, al CFT Santo Tomás y a la cadena de colegios Santo Tomás.

Juan Hurtado tiene como brazo derecho en esta área de sus negocios a Marcos Büchi, el hermano del ex Ministro de Hacienda, que ocupa el cargo de "director ejecutivo". Hurtado preside ENTEL, es accionista de Pucobre y del Consorcio Nacional de Seguros, dueño de inmobiliarias, es uno de los grandes beneficiados con las privatizaciones de ex empresas públicas. 
La Universidad Santo Tomás tenía 29.526 alumnos en 2013, a los que se suman los del IP, el CFT y los colegios.

El inversionista Tim Purcell, fundador de Linzor Capital y José Said, controlador de Embotelladora Andina y de Parque Arauco, son socios de Linzor Capital.

El ex Ministro de Hacienda, Hernán Büchi, ex candidato presidencial en 1990, es el presidente de la junta directiva Universidad del Desarrollo, una de las doce investigadas por lucro. Ahí estuvo también, durante mucho tiempo como vicepresidente, otro ex candidato presidencial, Joaquín Lavín Infante, quien volvió después a pesar de haber dicho que había vendido. Pero fue acogido de nuevo en la Universidad del Desarrollo, lo mismo que el ex ministro Secretario General de la Presidencia, Cristián Larroulet, quien al parecer nunca vendió. Él habló alguna vez de un fideicomiso ciego, pero no debe haber sido tan ciego, porque siguió en la Universidad del Desarrollo.

Luego está desde la fundación el Rector Federico Valdés Lafontaine, conocido en los ámbitos de la Universidad de Chile porque fue el Presidente de Azul-Azul. Los otros socios son del grupo Penta, que surgió gracias a privatizaciones en tiempos de dictadura y que es dueño del Banco Penta y Compañía de Seguros Penta e importantes negocios inmobiliarios. Sus máximas figuras son Carlos Alberto Délano, "el choclo", y Carlos Eugenio Lavín. Acaba de conocerse un problema muy serio con el señor Hugo Bravo López, que ha sido formalizado por delitos de alta complejidad y por problemas tributarios tremendamente graves, investigado también por la Fiscalía de Delitos de Alta Complejidad. Bravo fue por años gerente de sociedades del grupo Penta, el que integraba hasta hace muy poco. Relacionado con esta universidad está también el diputado y presidente de la UDI Ernesto Silva Méndez, quien hasta asumir ese cargo era miembro de la directiva de la UDD.

Este grupo de la Universidad del Desarrollo, nacida en Concepción en febrero de 1990, es dueño de la Inmobiliaria Ainavillo y de otras sociedades relacionadas con ella.

Así como en la Universidad del Desarrollo la vinculación con la UDI es evidente -y uno puede seguir extendiéndose en este punto con otros nombres de decanos y profesores- hay otras universidades donde también destaca la presencia de personajes de Renovación Nacional. Es el caso de la Universidad Autónoma, la universidad de los Ribera: el ex Ministro de Justicia de Sebastián Piñera, Teodoro Ribera Newman, ha sido figura clave y comparte la propiedad con su padre y sus hermanos. Había sido su rector hasta que fue nombrado por Piñera Ministro de Justicia, pero se vio obligado a renunciar al gabinete a fines de 2011 y se volvió a la universidad. Esta tiene su Casa Central en Temuco, pero se ha expandido a otras regiones, incluyendo Santiago. Además, los Ribera compraron el instituto Incacea, 
que estaba en acreditación cuando estalló el escándalo de la CNA, lo que salpicó al ex ministro. Además son propietarios de un colegio en Temuco.

Aunque la Universidad Mayor no está en la lista de las investigadas por lucro, siempre me ha llamado la atención porque su junta de gabinete parece una reunión de gabinete de Pinochet, incluso hasta ahora: el señor Ricardo García Rodríguez, quien fue ministro del Interior, ha sido su histórico Presidente, en compañía del ex ministro de Odeplan y Secretario General de Gobierno, Sergio Melnick, quien pertenecía al mismo grupo de Juan Antonio Guzmán Molinare y que estaba en estas comisiones junto a Federici y Saieh en los ochenta. Melnick fue Decano designado en la Facultad de Economía de la Universidad de Chile, que en ese tiempo se llamaba Facultad de Ciencias Económicas. Allí trataron de generar toda una escuela de pensamiento para implantar el modelo neoliberal, gracias a Saieh y Melnick. Actualmente Melnick, además de estar en la junta directiva de la Universidad Mayor, es columnista del diario La Segunda. Integra ese directorio también el ex ministro Jorge Prado Aránguiz y el abogado Mario Arnello. Su Rector es Rubén Covarrubias, que encabeza los movimientos en pro del apoyo estatal a las privadas y de todas las manifestaciones anti educación pública. René Salamé, el último Ministro de Educación de Pinochet, es Vicerrector Académico y de Aseguramiento de Calidad. La Universidad Mayor tenía casi 20 mil estudiantes en 2013.

Un caso curioso es el de la Universidad de Aconcagua, que la compró en 2008 Gonzalo Vial Concha, quien era socio de la pequeña Universidad de Rancagua. Hijo del empresario de pollos y cerdos Gonzalo Vial Vial, el principal accionista de Graneles de Chile, criador de caballos y aficionado al rodeo. Los Vial son dueños de Agrosuper, Superpollo y La Crianza. Así, los escándalos de Freirina por la contaminación de los cerdos y la colusión en la venta de los pollos también tienen su arista que los vincula con el negocio de las universidades. Si saben o no de universidades no está claro, pero llama la atención el crecimiento de esta entidad, que ni siquiera está acreditada. Además de las sucursales que la Universidad de Aconcagua tenía en La Ligua, San Felipe, Limache, Viña del Mar, Gonzalo Vial mantuvo su sede de Rancagua y en los últimos años ha abierto en más de 20 ciudades del país.

La lista podría continuar y seguir con muchos otros personajes involucrados. Pero lo que podemos concluir es que al darle una mirada a estas cifras y estos nombres, uno se puede imaginar que estamos al medio de una batalla dura, fuerte, porque están los intereses de los guardianes del lucro detrás de todos estos números. Gracias.

Andrea Valdivia: Gracias, María Olivia. Dejo con ustedes ahora a Manuel Antonio Garretón. 
Manuel Antonio Garretón: Yo me voy a aprovechar del diagnóstico realizado por María Olivia, no para volver sobre eso, salvo en algunos hechos puntuales que deba retomar, sino para plantear las cosas desde otra perspectiva y construir una cuestión relativamente acumulativa entre nosotros. ¿De qué se trata el problema hoy respecto de la educación superior? Chile no tuvo modelo explícito de educación superior hasta 1981. Lo que tuvo fue un modelo de universidades, donde el principio no era fundacional, sino que la fundación del sistema de educación superior coincidía con la fundación de instituciones, es decir, se iban reuniendo instituciones, todas ellas precedidas de un complejo debate, sobre la tarea, misión, definición y concepto de universidad. Y afuera, la que preside Andrés Bello y la que presiden después los sacerdotes u obispos, o la que va a tener la logia masona en Concepción o la que tiene el grupo en la Universidad Austral. Hubo ahí, y eso es muy importante tenerlo en cuenta, un debate sobre para qué una universidad y en qué le interesaba al país o al Estado una universidad.

Lo que hubo es que se fueron creando instituciones de acuerdo a una idea general de una universidad al servicio del proyecto histórico de nación, de República. Eso va variando y requiere especialmente fuerza desde los 30 para delante, con la idea de la vinculación de la Universidad con un modelo de desarrollo que era el de la industrialización. Industrialización capitalista, sí, pero industrialización con un fuerte papel del Estado. Entonces, lo que las universidades en su acto fundacional no cumplían, se resolvía por vía de reformas que, en general, eran propiciadas por los movimientos estudiantiles, los sectores académicos o el Estado mismo. Por ejemplo, la Universidad de Chile pasa a ser efectivamente una universidad nacional cuando genera sus sedes. En ese sentido uno puede decir que las sedes eran un acto fundacional. Pero quiero insistir en que, lo que no hubo, fue un acto fundacional de un sistema de educación superior, porque no hubo ningún proyecto.

En cambio, en 1981 o un poco antes, sí asistimos a un proceso de fundación de un sistema de educación superior. Ese es un dato, a mi juicio, fundamental, que al igual que la creación de las universidades, obedecía a un proyecto y visión de sociedad, distinto de la visión que tiene la Universidad Católica y la Universidad de Concepción. Sin embargo, uno diría que los principios básicos desde los cuales una universidad tiene responsabilidades respecto a una comunidad local o nacional, de algún modo se compartían y debatían. Lo que hay aquí es la creación de un modelo de educación superior, que uno a uno contradice los principios del sistema anterior, porque se basa en un modelo o proyecto de sociedad inédito en Chile. Se trata, como bien lo hicieron, de refundar el país, y si usted quiere refundar un país, tiene que refundar su sistema educacional.

Ahora, la OCDE marcó muy bien el principio fundacional para el sistema de educación, pero cuando plantea la hipótesis de que el sistema educacional está 
ligado a un modelo social, entonces no puede decir que el principio de modelo educacional es también el principio del modelo socioeconómico. Y la OCDE dijo claramente que el modelo educacional, es decir, el modelo socioeconómico, no está formado y no tiene como consecuencia la desigualdad, sino que está creado para generarla. En la medida en que esto es así, el sistema de educación superior tiene como fin la generación de desigualdad. Y todo lo que ha dicho María Olivia está en ese punto.

Ahora bien, cuando Chile recupera la democracia, con todos los defectos que tenga esa democracia, los gobiernos que siguieron tuvieron que enfrentar el dilema de qué hacer frente a la educación superior. Hicieron el diagnóstico de que el modelo de educación superior chileno era adecuado y que había que consolidarlo, frases textuales de la Comisión de Educación Superior creada por el Presidente Aylwin, con un voto disidente en todos sus puntos, que era el mío. La política oficial fue "no hay que refundar, hay que consolidar". Por supuesto que se consolidó con algunas correcciones, de modo que yo diría que el modelo que se siguió fue un modelo de corrección, no de refundación, pero todas esas correcciones, sin plantearse un nuevo principio, iban en la línea de consolidación del modelo heredado de la dictadura.

Además de muchas críticas, entre 2006 y 2011 lo que se plantea como cuestión fundamental es la refundación de un modelo de educación superior que pretende refundar el modelo educacional, porque lo que está en juego es la refundación del modelo económico neoliberal y de su modelo político, la constitución. Por lo tanto, lo que queda planteado como proyecto nacional, tal como en 1938 o en los años veinte y treinta para adelante, era industrializar el país. Para eso había que tener un determinado sistema o tipo de universidades, tal como en los años sesenta se plantea el problema de hacer una Reforma Agraria como proyecto fundamental, como proyecto histórico. Una transformación enorme que implica a las reformas universitarias de los años sesenta o el modo en que se plantea un proyecto de socialismo o un proyecto neoliberal. La cuestión planteada hoy día, históricamente en la sociedad chilena, se haga o no se haga, se cumpla o no se cumpla, es la superación de la sociedad postpinochetista con su modelo económico social, incluido su modelo de educación superior y su modelo político.

Sin embargo, como no se refunda de la noche a la mañana, lo que usted tiene que hacer desde hoy es corregir, pero corregir en la línea de la refundación, no en la línea de la consolidación, lo que implica tener un principio y una estructura como horizonte para realizar políticas. Entonces, la cuestión central es esta: refundar el modelo y sistema de educación superior, que estoy de acuerdo con María Olivia en que puede ser un caos, pero se trata, digamos, de un sistema de instituciones que se basa en su creación, en su funcionamiento y en el acceso a ella, a partir de los principios de mercado. Por lo tanto, se trata de cambiar eso hacia un sistema institucional de 
educación superior que tenga como principios el derecho universal de la educación superior, el principio democrático de desarrollo igualitario, etc. Frente a eso, es importante también discutir lo siguiente: ¿Cuál es la tarea de una universidad en lo que se llama hoy la sociedad del conocimiento, independientemente que nos guste $\mathrm{o}$ no nos guste la denominación? Porque una universidad en un mundo de internet y Google no es lo mismo que una universidad de la sociedad industrial, no puede ser lo mismo, entonces implica también pensar en eso, y ese debate aún no se ha hecho.

La primera cuestión es que hay que tener un principio de horizonte, que es un principio de oposición, sobre el cual generar una nueva estructura. Dicho eso entonces la pregunta es: ¿qué tipo de nueva estructura? El modelo actual consagra, como decía María Olivia, tres niveles: las universidades, los institutos profesionales y los centros de formación. Y dentro de las universidades, una serie de distinciones con el modelo propiamente tal consiste en el predominio creciente de la universidad privada con fin de lucro real, no con fin de lucro formal, porque esto no se puede por ley.

De tal modo, la cuestión es qué tipo de estructuras puede uno proponer a partir de un principio y una idea de educación superior y de universidad distinta. Mi impresión es que deberían sacarse del nivel de educación superior a los centros de formación técnica para dejarlos en un nivel distinto y con otro nombre al de educación secundaria y superior. Generaría, por supuesto, una dirección estatal al respeto y realizaría una muy amplia política de compra o expropiación simplemente y de fundación por parte del Estado. En cada uno de estos niveles de lo que se llama educación postsecundaria, donde hay predominio estatal en recursos, matrículas, recursos humanos y número de instituciones, eso es un principio fundamental. Y respecto a los institutos profesionales y los centros de formación técnica, tiene que eliminarse el fin de lucro y tener en cada ciudad una institución pública de centro de formación técnica y en cada región, por lo menos, dos o tres institutos profesionales.

Respecto de las universidades, mi impresión es que hay que reducir drásticamente el número y que tiene que aumentar la oferta estatal. Porque el principio de gratuidad de la educación superior no tiene sentido en el sistema actual, donde gratuidad significa que el Estado subvenciona las universidades privadas y, por lo tanto, no se obliga a sí mismo a generar oferta de educación pública. Ahora bien, yo entiendo que como medida transitoria debiera estar fundado en unos 20 años más un nuevo sistema de educación superior radicalmente distinto al actual. Para ello tendrán que buscarse mecanismos mediante los cuales la Universidad de Chile sea creada por ley y se salte la estupidez de los sistemas de acreditación actuales para generar un sistema a través del cual las universidades tengan que cumplir ciertos requisitos para llegar a ser formadas por ley, como fue en la historia de Chile, para que tengan 
que cumplir con una serie de características, por ejemplo, todas tienen que tener concursos públicos y respetar el principio del pluralismo, de participación, etc. De este modo, las universidades de mala calidad no podrían cumplir.

Mi impresión es que hay que optar por una medida institucional. Yo agregaría un tercer nivel a la educación superior y sacaría la educación de formación técnica, fortaleciéndola mucho, pero en un nivel distinto. Además, agregaría en el nivel de educación superior el de colegios o college, que dan un grado de bachillerato. Porque uno de los grandes problemas que tiene el modelo es que la barrera de entrada era cero; todos sabemos que era más fácil crear una universidad que un sindicato o un club de fútbol, o hasta una botillería, entonces no se puede tener un sistema universitario con esa barrera de entrada que tuvo al comienzo. Ahora todo esto es un problema político enorme, pero señalo que aquí hay que tener un horizonte.

A mi juicio, el problema fundamental de la Universidad de Chile es que, por un lado, tiene que liderar el debate sobre qué es una universidad en la época actual y, por otro, debe trabajar en su propia definición de qué es ser una universidad nacional. Porque lo que le va a dar el carácter de nacional a la Universidad de Chile es al menos tener una serie de beneficios, que se los merece y debiera tenerlos como cuestión básica, que ser la que propone un sistema de educación. Por lo tanto, yo creo que el tema es, insisto, refundar el sistema de educación superior, replanteando una idea de universidad acorde a la época y con un modelo estructural que uno por uno contradiga los principios en los cuales está generado el actual sistema de educación superior.

Andrea Valdivia: Muchas gracias, Manuel Antonio. Ahora, en la última intervención en esta ronda, responde Jesús Redondo.

Jesús Redondo: Yo creo que hay una articulación bastante consistente entre tres elementos clave que han aparecido ya en la mesa anterior y en esta. En primer lugar, creo que hay una conexión muy grande entre, en primer lugar, el concepto de Estado subsidiario (el Estado sólo tiene razón de ser para apoyar la iniciativa privada), en segundo lugar la opción de un modelo de desarrollo como plataforma comercial (Chile no necesita hacer industria, basta con que sea una buena plataforma comercial con el Asia Pacífico y con esto ya es suficiente) y tercero el modelo de educación, que más que responder a las necesidades de la sociedad chilena, se convierte en lo que se llama una nueva industria, que en realidad es un nuevo mercado. De hecho, de todas las universidades que se han generado, ninguna prácticamente merecería el nombre de universidad, sino instituciones de docencia superior, porque el negocio está ahí. Y luego hay que fijarse en que, curiosamente, la LOCE sigue vigente en 
todos los artículos que se refieren a la educación superior, sobre todo en lo que respecta a la educación básica y media.

En ese sentido, el estado actual de cómo se ha llegado a esta situación de aceptar el modelo y apostar por consolidarlo, tiene que ver con una alianza estratégica, consciente o inconsciente, de neoliberales y neoconservadores. Ahora, hay que poner atención a nosotros, los tecnócratas formados en las universidades, que apuestan como valor principal por la eficiencia a corto plazo. Analicemos la privatización que se ha producido en las universidades, en concreto en la Universidad de Chile como líder del sistema universitario que se gestiona en base a modelos de eficiencia a corto plazo. Podemos analizar toda la dinámica en la que nos hemos metido a nivel nacional, pero si miramos lo que ha pasado en las universidades europeas, es exactamente lo mismo, es decir, el neoliberalismo ha llegado a consolidarse porque le hemos prestado el valor de la justificación de la ciencia desde las universidades.

En ese sentido, la Universidad tiene un serio problema de legitimidad y de hegemonía precisamente porque es la que mejor servicio ha prestado a este modelo en los últimos 50 años a nivel mundial. Dicho esto, el caso chileno es extremo, porque si se compara a nivel internacional, es el modelo de educación superior más desregulado. Primero, porque cada universidad puede crear la carrera que se le ocurra y puede dar ese título aunque no exista en ningún lado y aunque no sirva para nada. Segundo, es el modelo más privatizado, creo que incluso le ganamos en proporción a Brasil, que es el segundo, con más privatización y más mercantilización, porque se ha basado en un mito de igualdad de oportunidades y ascenso social a través del estudio universitario. Hoy en día existe una cantidad de ilustrados cesantes en muchas profesiones, porque no es suficiente tener un título. Otro aspecto es, que desde el punto de vista de costos, es el más caro del mundo: los títulos chilenos son los que más cuestan en todo el mundo, a valor equiparable de salarios. Al mismo tiempo, es el sistema más ineficiente, porque no hay una evaluación y control real de los resultados que tiene la formación, porque los modelos de acreditación son también un nuevo mercado. Lo mismo pasa en el modelo educativo que no mejora la educación, porque lo que inventamos para mejorarla son nuevos mercados, esto es, no para la calidad, sino para nuevos negocios.

Además, el elemento constitutivo de este sistema es la segregación mayor, es decir, si antes la separación era ricos-pobres, hoy en día tenemos 17 matices: están, entre otros, los ricos-ricos, pero también los ricos que quieren serlo, y para cada uno de ellos hay un producto dentro del supermercado, pero también dentro de la educación y la universidad. Y el mayor negocio lo hacemos además con los más pobres, porque para eso creamos el Crédito con Aval del Estado, que de paso sirve para endeudar a futuro a esos jóvenes a los que no les va a servir de nada el título que sacan. En ese sentido, es una estructura que genera un proceso permanente 
de enriquecimiento ilegítimo, porque, por una parte, es ilegal y se supone que no puede haber lucro en las universidades y, por otra, ejecuta un fraude con el uso de los recursos públicos.

A mi modo de ver, ese es el diagnóstico de la situación en que nos encontramos como universidades, tanto con un tema de mercantilización en el ámbito de lo externo, como con un proceso interno de privatización dentro de las propias universidades tradicionales y públicas. Entonces, tenemos que hacer un doble trabajo, no solamente para cambiar el modelo de educación superior, sino también para cambiar la forma de ser universidad pública, a la cual nos hemos acostumbrado en los últimos 40 años.

Andrea Valdivia: Muchas gracias, Jesús. Creo que los tres expositores han hecho un buen panorama no sólo del sistema actual, sino de los procesos históricos que ha vivido nuestro país y que se desencadenan en el sistema que tenemos. Manuel Antonio Garretón planteó el desafío de si queremos transformar no tan sólo el sistema educativo, sino refundar nuestra sociedad y se preguntó cuál debe ser el rol de la Universidad de Chile en este debate. A partir de lo reflexionado, quisiera pedirles a los integrantes de esta mesa que desde de su experiencia en formación de profesionales identifiquen algunos elementos que nos ayuden a concretar la relevancia o del papel que tiene nuestra Universidad en este proceso transformador: ¿Cómo podríamos enfrentar el desafío de pensar un nuevo sistema de educación superior desde la Universidad de Chile?

María Olivia Mönckeberg: Lo que han dicho tanto Jesús Redondo como Manuel Antonio Garretón ha sido muy interesante. Manuel Antonio señaló que el rol de la Universidad de Chile es, justamente, lo que tratamos de hacer todos los días con los estudiantes, es decir, mirar el sistema o el "no sistema" para tratar de reformarlo. Creo que no podemos dejar de pensar en la urgencia que esto requiere y en la importancia del aporte de cada uno para que este país tome un poco de conciencia, sobre todo en nuestro contexto de un sistema de medios de comunicación que tergiversan y manipulan constantemente y que no dan espacios para los debates. Tener este tipo de coloquio, entonces, es esencial para poder generar cambios. Cambios que son fundacionales -como dice Manuel Antonio-, y el debate debe darse en muchos niveles a la vez: sala de clases, sala de profesores, el auditorio donde estamos, entre otros espacios. Es todo eso y, a la vez, nuestra relación con la sociedad; en ese sentido tenemos que asumir como académicos y estudiantes de la Universidad de Chile esta responsabilidad. Al respecto, Jesús dijo algo crucial: el sistema que se instaló, esa privatización de la investigación, por ejemplo, a través de 
los Fondecyt, hizo perder no sólo el trabajo en equipo, sino también el sentido de comunidad y, finalmente, el sentido de universidad.

Si uno piensa en un sistema nuevo, coincido con Manuel Antonio en que hay que tener claros los horizontes y definir de qué estamos hablando cuando hablamos de universidad hoy. Al respecto, me parece que un paso esencial es el paso hacia la gratuidad y ese paso a la gratuidad va a requerir de calidad y lo que entendamos por calidad. La verdad es que tenemos más preguntas que respuestas, por eso tenemos que ir avanzando en las conversaciones de manera profunda, pero rápida, porque esto ya es demasiado urgente.

Manuel Antonio Garretón: No discrepo con ninguna de las ideas que se han dado acá, tanto en la intervención de María Olivia como en la de Jesús. Brevemente quiero decir: ¿de dónde vinieron las ideas con los impulsos para cambiar, reformar y mejorar lo que había hasta el año 73? Yo diría que, obviamente, estas ideas vinieron de las mismas instituciones internamente. En el caso de los años sesenta, el liderazgo vino de las universidades católicas, por la simple razón de que eran las más atrasadas al respecto y tenían que hacer prácticamente una revolución para transformarse de colegios particulares en universidades. En cambio, en las universidades, independientemente de las estatales, el gran debate fue sobre la lucha por el poder universitario, porque estaba vinculado a lo que estaba ocurriendo en el país; de ahí salieron las ideas de qué hacer. Ahora, ¿de dónde salió el modelo fundacional del régimen militar? Básicamente salió del Estado, no de las universidades. Entonces la pregunta es: ¿De dónde han venido las ideas para corregir consolidando? Esto ha provenido de la División de Educación Superior que tiene una oficina en el Ministerio de Educación. Entonces, yo creo que el desafío de refundación debe venir básicamente de las universidades estatales y dentro de eso yo creo que tiene que ser la Universidad de Chile la que promueva el debate al interior de las universidades estatales. Si a mí me preguntan: ¿Qué haría?, yo creo que hay que hacer lo que se hizo en la Universidad de Chile en un momento cuando se trataba de cambiar nada más algo interno: el estatuto, que son las convenciones que se hacen en los años 96 y 97 y lo que se hizo en los años sesenta con las convenciones de la FECH y las grandes convenciones y congresos de profesores. Hay que hacer una movilización de este tipo al interior de las universidades, donde se discuta no sólo la reforma interna de la universidad, sino también la propuesta de país.

Entonces la idea es desencadenar un proyecto fundacional que, como he dicho, no se hace de la noche a la mañana, pero desencadenar un proceso implica tener ideas, horizontes, y eso tiene que venir de una propuesta que haga la Universidad para la misión de educación superior. Porque la idea de pensar el sistema de educación era del conjunto de universidades, pero sobre todo de la Universidad de 
Chile. Acuérdense de la tarea que tenía la Universidad de Chile respecto al sistema de universidades privadas. Yo fui alumno de un colegio privado y tenía que rendir exámenes ante profesores del Estado. En una época la Universidad de Chile tenía tuición sobre los títulos. No se trata de volver a antiguas situaciones, sino de decir que es desde las universidades estatales y con la Universidad de Chile como líder de ese proceso, donde tiene que salir la propuesta para los próximos 100 años. Insisto, estamos en un momento fundacional o refundacional, pero no hemos desencadenado el proceso y esa es nuestra tarea. Por supuesto, como decía sobre todo Jesús, eso implica también convención y congresos donde se discute nuestra propia estructura y misión.

Andrea Valdivia: Gracias, Manuel Antonio. A continuación, Jesús Redondo.

Jesús Redondo: Yo comparto que el sistema de educación superior es más complejo que las universidades y que claramente vamos a tener que pensar distintos tipos de instituciones. No necesariamente instituciones diferentes, pero sí diferentes niveles entre los institutos superior tecnológicos, lo que podrían ser las universidades que se llaman docentes (pero que podrían ser universidades como el College regionales) y las universidades complejas nacionales, además de, obviamente, una articulación entre ellas. Un trabajo de liderazgo como el que se está señalando hoy es un liderazgo distribuido, es decir, no es alguien que lidera solo (ni siquiera la Universidad de Chile), sino alguien que es capaz de generar, en primer lugar, un proceso con las universidades estatales. No obstante, yo sí creo que uno de los temas pendientes que tiene la universidad es recuperar legitimidad y hegemonía de cara a la sociedad actual. En ese sentido, se requiere abordar algunas tareas que suponen algunos trabajos hacia adentro, como son, por ejemplo, trabajar para una sociedad menos desigual, más justa y basada en el conocimiento, pero en un conocimiento que integre el conocimiento científico, social y cultural. Porque a veces la universidad ha dado una excesiva preponderancia al conocimiento científico y a los otros los ha colocado como folclor marginal, pero no se le da el valor que tiene para el desarrollo de las sociedades. El mejor ejemplo es el Transantiago, porque no le faltó solamente conocimiento científico, sino también social y cultural. Lo mismo nos puede pasar en educación, sanidad y en cualquier otro tema. Entonces yo creo que la universidad tiene que integrar esos saberes, es decir, hacer una "ecología de saberes".

También creo que debe trabajarse el tema del desarrollo de la identidad nacional, recogiendo lo que decía el Profesor Salazar: una identidad nacional muy diversa que requiere también de lo local. En ese sentido, lo local está menos reñido con lo global que lo nacional, de modo que desarrollar lo local puede ser una muy buena estrategia para asegurar el desarrollo de identidad de lo propiamente chileno 
y latinoamericano en el largo plazo. En ese aspecto, la universidad tiene un trabajo que es un proceso reconstituyente de la propia realidad. Yo creo que también hay una pequeña apuesta porque las universidades tengan un rol en la reconstrucción del sistema de educación chileno. Yo creo que las universidades tienen que apostar porque esa tarea sea suya. En ese sentido uno de los aspectos es desarrollar el proceso democrático dentro de las propias universidades estatales, porque hay unas que han estado muy lejos de eso. Yo creo que también hay un tema de innovación, pues la universidad ha quedado anquilosada en procedimientos y esquemas que son un poco antiguos, por ejemplo, en el concepto de la educación continua, porque no podemos hacer compartimentos estancos entre el pregrado y el postgrado, entre la formación técnica que se da en un lado y la que luego puede ser universitaria, es decir, hay que hacer caminos mucho más rápidos de recorrido y también caminos más diversos. Muchos de los jóvenes actuales no necesitan dedicar el 100\% de su tiempo a estudiar en la universidad, pero sí pueden dedicar el 30\% mientras están trabajando y hacer sus carreras universitarias en más tiempo. Por otra parte, la universidad cobra aranceles por el año completo y por la totalidad, cuando resulta que muchos estudiantes podrían estar estudiando con créditos parciales y hacer un pago parcial.

Existen también otros temas, como la incorporación de las nuevas tecnologías en los procesos de docencia, investigación y gestión, o la transferencia tecnológica con el sistema público, los movimientos y las organizaciones sociales. Eso también es transferencia y eso también requiere el trabajo en las universidades. Todo esto debiera realizarse en un modelo de red, es decir en una red nacional y latinoamericana de universidades públicas, que trabajen investigación, desarrollo e innovación, recuperando lo público dentro del desarrollo de los Estados nacionales. Por último, creo que un tema clave es la pertinencia social del conocimiento que se desarrolla en las universidades e institutos de educación superior, en relación a las problemáticas reales de los territorios, familias y ciudades, tal como señalaba el profesor Gabriel Salazar.

Andrea Valdivia: Muchas gracias a los participantes de esta mesa. Ha sido interesante no sólo mirar el sistema actual, sino también pensar la universidad y, en particular, la Universidad de Chile, asumiendo este desafío de refundación, como decía Manuel Antonio Garretón, pero también haciéndose cargo del contexto global y nacional. Jesús daba algunas pistas de cómo podríamos llegar a hacer funcionar este proceso transformador. Esto es un desafío para nosotros, que somos parte de esta universidad como comunidad educativa y que tenemos una responsabilidad para que esas transformaciones se proyecten hacia el sistema de la educación superior de nuestro país. Muchas gracias a todos y todas. 
Coloquio: "Reforma educacional y Educación Pública" Mesa 2: La Universidad de Chile y el sistema de educación superior

María Olivia Mönckeberg Pardo

Profesora titular

Directora del Instituto de la Comunicación e Imagen de la Universidad de Chile

Premio Nacional de Periodismo 2009

Santiago, 19 de agosto de 2014 

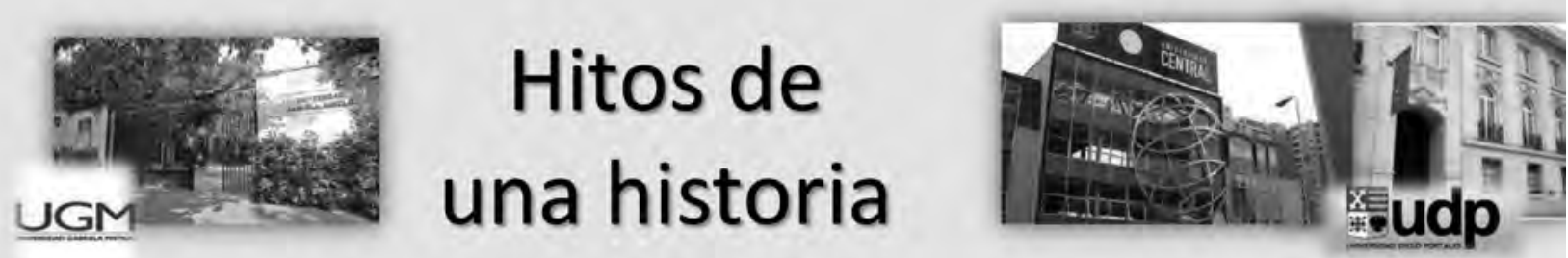

A fines de 1980 y comienzos de 1981, cuando se estrenaba la Constitución de 1980, se promulgaron una serie de decretos conocidos como "Ley General de Universidades".

Mientras se debilitaba la Universidad de Chile, se autorizó la fundación de universidades privadas, un elemento clave de la nueva política. Concibieron también los Institutos Profesionales y los Centros de Formación Técnica.

Cambió el sistema de financiamiento: AFD, AFI y créditos y se implantó la política de fondos concursables (Fondecyt) para la investigación.

Ese año partieron también la reforma previsional y la salud privada: nacieron las AFP y las Isapres.

Sólo tres universidades privadas se estrenaron al comenzar los'80: la Universidad Gabriela Mistral, la Diego Portales y la U. Central. El resto fue creado al finalizar la dictadura.

El último día de su gobierno, el 10 de marzo de 1990, Pinochet, dictó la Ley Constitucional de Educación, LOCE, que dejó atado el modelo educacional. 


\section{Matrículas pregrado e ingresos 2013 sistema educación superior}

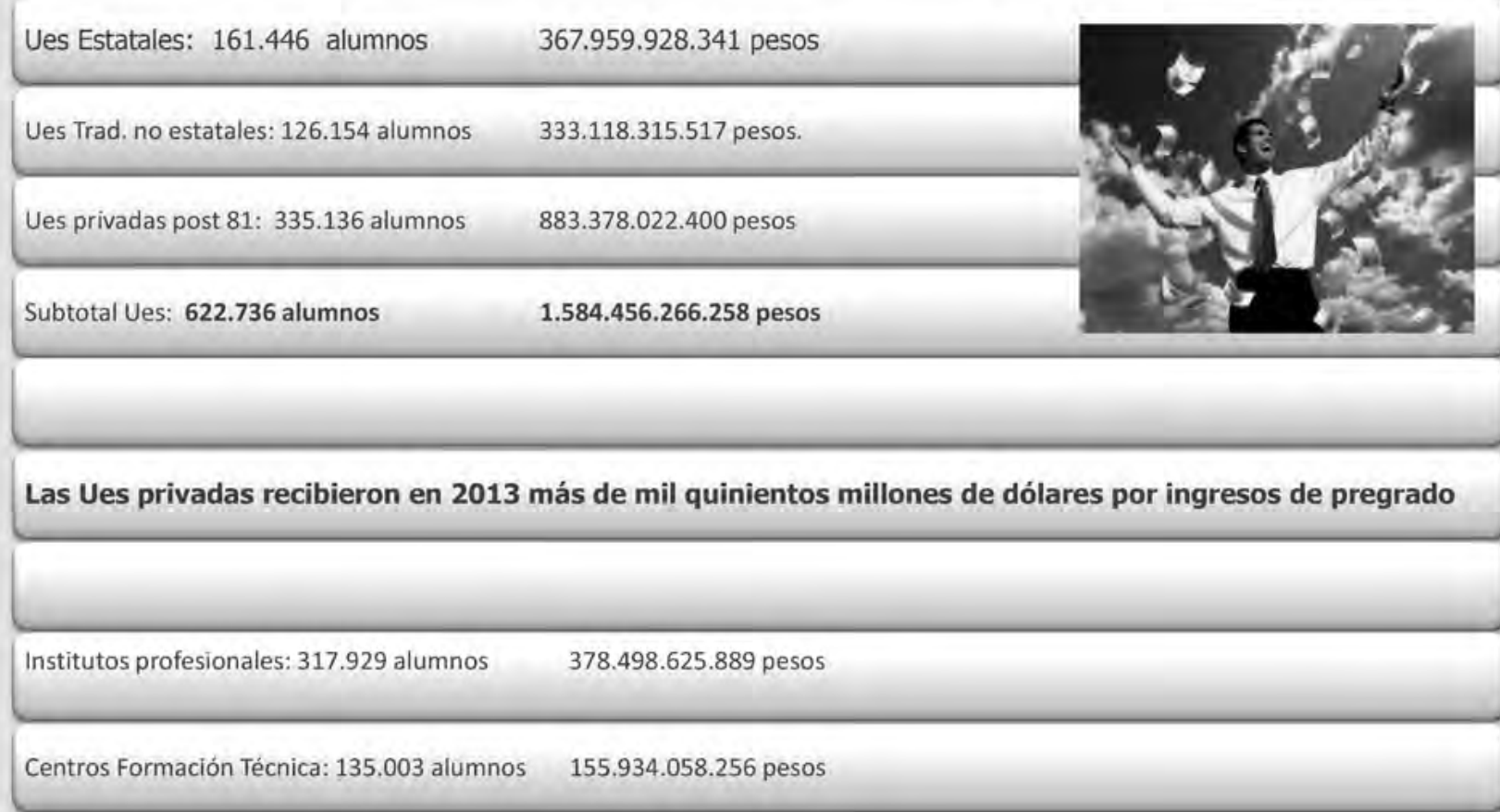




\section{El desproporcionado peso de las instituciones privadas}

Del total de los alumnos universitarios, un $53,82 \%$ está en privadas post 81 ; un $25,93 \%$ en estatales, y un $20,2 \%$ en las del Cruch no estatales.

Del total de los ingresos monetarios de las Ues, un $55,7 \%$ se lo llevan privadas post 81 ; un $23,2 \%$ las 16 estatales y un $21 \%$ las nueve del CRUCH no estatales.

33 años después de decretada la privatización, los alumnos de las universidades públicas sólo representan el $15 \%$ de todo el sistema de educación superior.

Incrementar esa proporción es necesario como parte del fortalecimiento de la educación pública. 


\section{Ingresos reales de las Ues entre 2005 y 20013 según estructura de la propiedad}

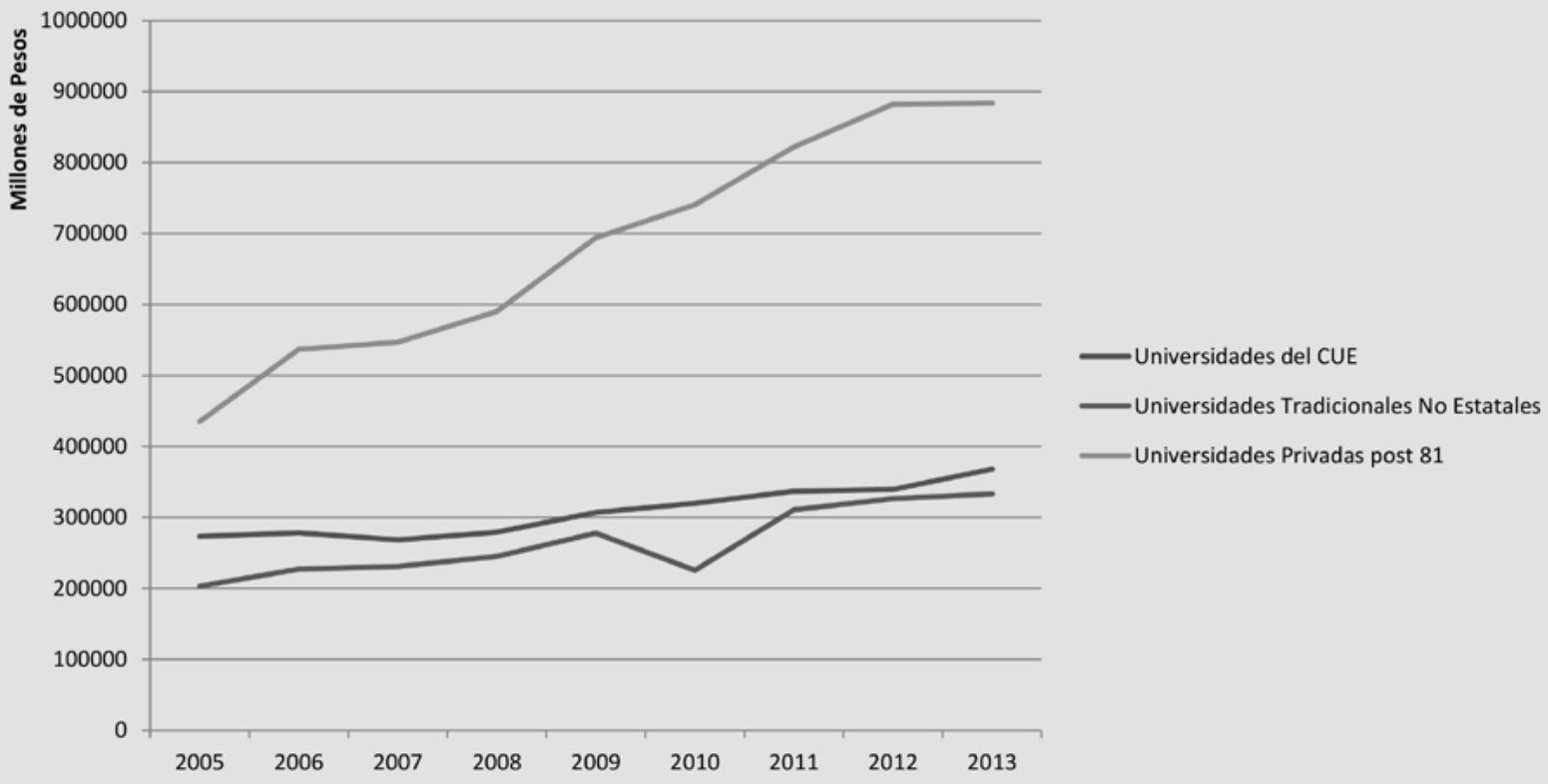




\section{Ingresos Reales de las Ues según estructura de la propiedad 2005- 2013 \\ (Fuente: Cálculos y gráfico Consultora Sintaxys sobre la base de estadísticas Mineduc)}

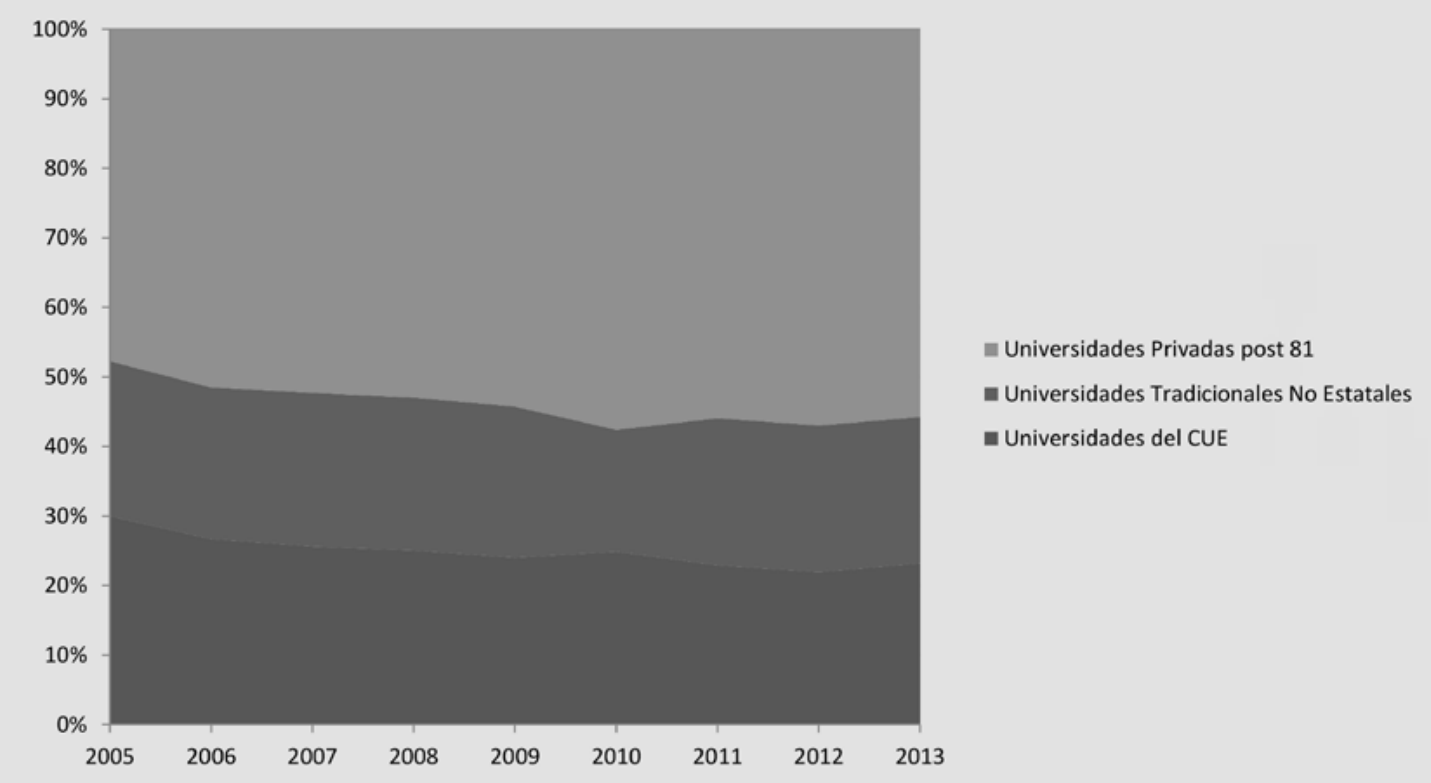




\section{Vouchers y recursos asignados por el Estado}

Fuente: "Financiamiento Fiscal a la Educación Superior 2013",

Contraloría General de la República

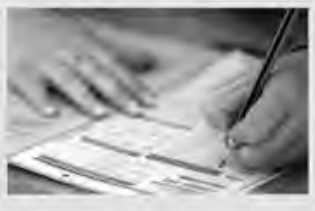

Según la Contraloría, en el año 2013, de acuerdo con los datos

de la ejecución presupuestaria, se distribuyó un total de M\$1.238.996.037 a educación superior.

Un $71,5 \%$ fue asignado a estudiantes, a través de créditos y becas, y un $\mathbf{2 8 , 5} \%$ a las instituciones.

Este monto representa aproximadamente un $4,2 \%$ del gasto total ejecutado por el gobierno central total.

El financiamiento fiscal a la educación superior hasta ahora está orientado mayoritariamente hacia los alumnos.

Los aportes recibidos por UNAB, San Sebastián, Santo Tomás, Autónoma; los institutos Duoc, Aiep e IP de Chile, y los CFT Inacap y Santo Tomás reciben aportes superiores a 8 de las 16 universidades estales.

De las 160 Instituciones de Educación Superior (IES) que recibieron financiamiento fiscal en 2013, hay 79 no acreditadas, entre ellas 15 universidades privadas. 


\section{El impacto del CAE}

Fuente: "Financiamiento Fiscal a la Eduación Superior 2013", Contraloría General de la República

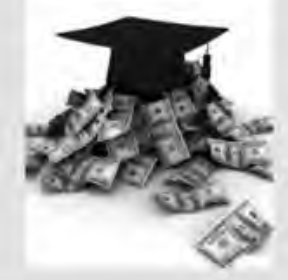

El $34,1 \%$ del financiamiento hacia los estudiantes (por la demanda) se efectuó en 2013 a través del Crédito con Aval del Estado (CAE).

El CAE aumentó un 10,5\% en 2013 respecto a 2012.

La gran parte de este se entregó a las Ues privadas post 81 (209 mil 495.421 millones de pesos), lo que representa un $69,3 \%$ de todo el CAE.

Se distribuyó en 27 instituciones. Destacan la U. San Sebastián, Santo Tomás, Andrés Bello, Autónoma y Las Américas.

A cada una de ellas se les destinó un monto mayor al total asignado a las 16 universidades estatales (sólo recibieron 16 mil 590.797 millones). 


\section{Universidades privadas y $\$$}

La mayoría de las universidades privadas post 81 ha hecho un gran negocio, aunque oficialmente pertenecen a corporaciones sin fines de lucro.

21 de las 35 existentes se fundaron gracias a la concesión gubernamental de la dictadura.
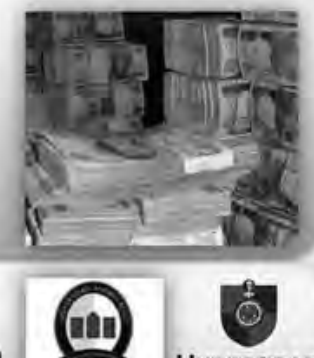

UNIVERSIDAD ANDRES BELLO MAYOR

UDD

Universidad del Desarrollo

Varias de las más conocidas están vinculadas a grupos de poder político y/o económico que se forjaron en dictadura o a quienes fueron ejecutivos o asesores de ese gobierno. Algunas están orientadas a la influencia ideológica, como la U. de Los Andes, que pertenece al Opus Dei. 


\section{2 investigadas por lucro}

\section{La Fiscalía investiga por lucro:}

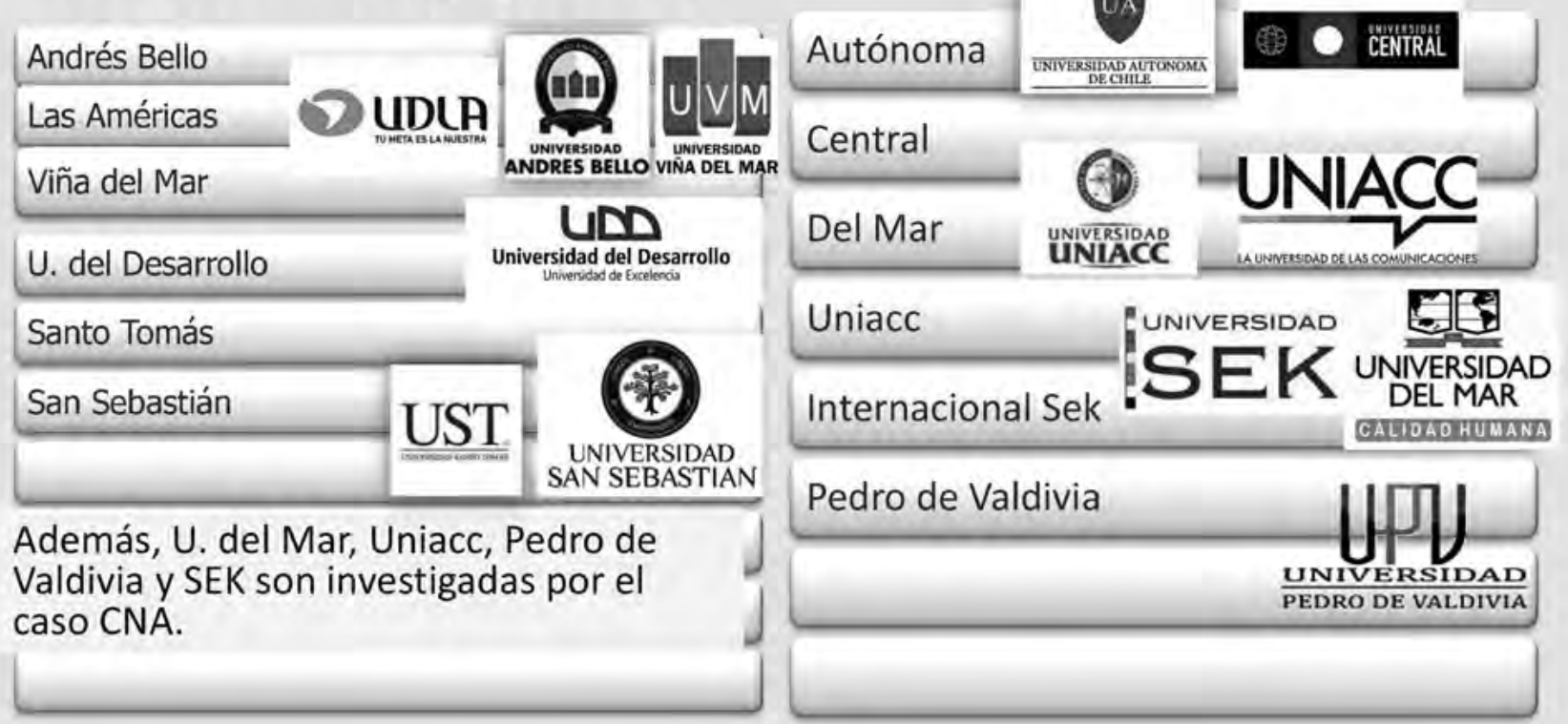




\section{Poder e Influencias}
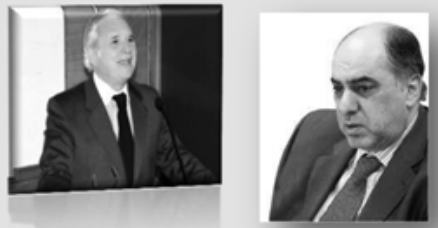

$>$ El grupo Laureate (ex Sylvan International),

bajo el control desde 2007 del fondo de inversiones estadounidense KKB (Kohlberg, Kravis, Roberts), inauguró las compraventas de "carteras de alumnos", al adquirir Las Américas y el Instituto Profesional Campus, en 2003.

$>$ Después adquirió la U. Andrés Bello en 2004

y el Instituto Profesional AIEP.

$>$ Hoy es dueño de las dos universidades privadas

con más alumnos y uno de los tres mayores institutos.

클

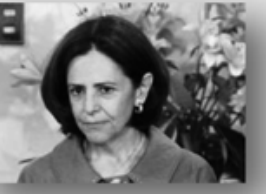

> Las Américas -con 34.455 alumnos en 2013- y Andrés Bello -con 45.233- suman casi 80 mil estudiantes: más del doble de la U. de Chile (37.173).

> En 2009 Laureate compró además la U. de Viña del Mar (7.610 alumnos) y la Escuela Moderna de Música.

> Hasta abril de 2014 presidió el directorio Herman Chadwick Piñera, ex presidente de CNTV. Dejaron también de ser directores Genaro Arriagada y Fernán Gazmuri (presidente de la Asociación Chilena de Seguridad). Otros hombres del grupo: Jorge Selume, ex socio de Alvaro Saieh; Manfredo Mayol, Julio Castro, ex jefe de Educación Superior. $>$ En la presidencia quedó José Pedro Undurraga, ex rector de Inacap y anterior rector de UDLA. $>$ Actualmente su rectora es Pilar Armanet y la decana de Educación Pilar Romaguera, ex subsecretaria. 


\section{Lazos y conexiones}

Preside la junta directiva de la Universidad Andrés Bello Juan Antonio Guzmán Molinari, ex ministro de Educación de Pinochet.

Guzmán Molinari fue el ministro que designó
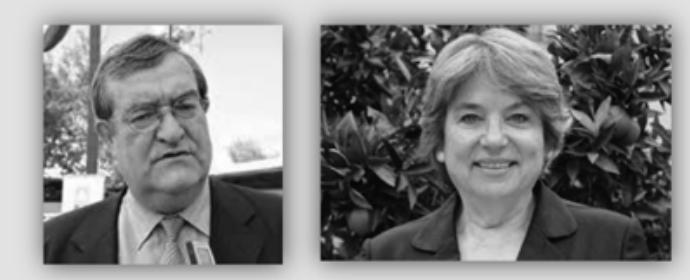
a José Luis Federici rector delegado de la U. de Chile en 1986.

$>$ Es presidente también de la Clínica Indisa y de la empresa de Comunicaciones Extend, entre otras actividades.

$>$ Cuñado del ex subsecretario de Hacienda Julio Dittborn, está casado con Paulina Dittborn Cordua, ex vicepresidenta del Consejo Superior de Educación, hasta 2011 prorrectora de Las Américas. Actualmente, es decana de Educación de la U. Santo Tomás y directora académica de los colegios Santo Tomás.

$>$ Guzmán y Paulina Dittborn, junto a José Pedro Undurraga -actual presidente de Las Américas- ,fueron clave en el control de Inacap y creación de la U. Tecnológica. 


\section{Más grupos en acción}

Juan Hurtado Vicuña, líder de uno de los principales grupos económicos actuales, "compró" en 2009 junto a fondo de inversiones Linzor Capital la mayoría de las acciones de la Corporación Santo Tomás. La entidad creada por Gerardo Rocha incluye la UST, instituto profesional, centro de formación técnica y colegios.
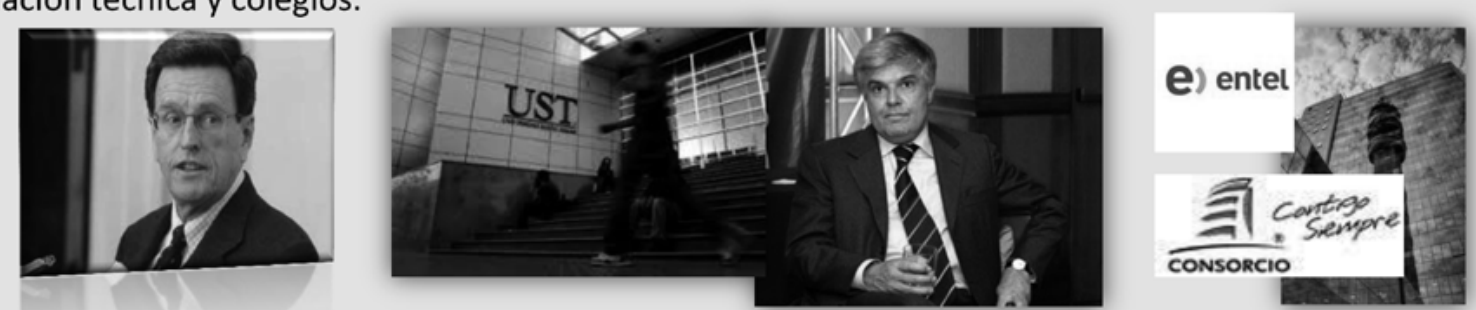

El presidente de Santo Tomás es Juan Hurtado, quien nombró a su brazo derecho Marcos Büchi Buc, hermano de Hernán, en el cargo de "director ejecutivo".

$>$ Hurtado preside ENTEL, es accionista de Pucobre y del Consorcio Nacional de Seguros, uno de los grandes beneficiados con las privatizaciones de ex empresas públicas, y dueño de inmobiliarias. Es cuñado del ex presidente de RN Carlos Larraín Peña.

$>$ El inversionista Tim Purcell, fundador de Linzor Capital y José Said, controlador de Embotelladora Andina y de Parque Arauco, son también socios de Linzor Capital.

$>$ En 2013, la Universidad Santo Tomás contaba con $\mathbf{2 9 . 5 2 6}$ alumnos.

$>$ A ellos se suman los del IP y del CFT y el grupo tiene además una cadena de colegios. 


\section{La Universidad del Desarrollo}

$>$ Preside la junta directiva de La U. del Desarrollo el ex ministro de Hacienda de Pinochet entre 1985 y 1989 , Hernán Büchi. Es socio de la UDD y sus inmobiliarias y sociedades relacionadas.

$>$ Joaquín Lavín, hasta asumir como ministro

de Educación en 2010, era vicepresidente de la junta directiva; otro de los socios fundadores y directivo por 20 años era el ex ministro de la Presidencia de Sebastián Piñera,

Cristián Larroulet.
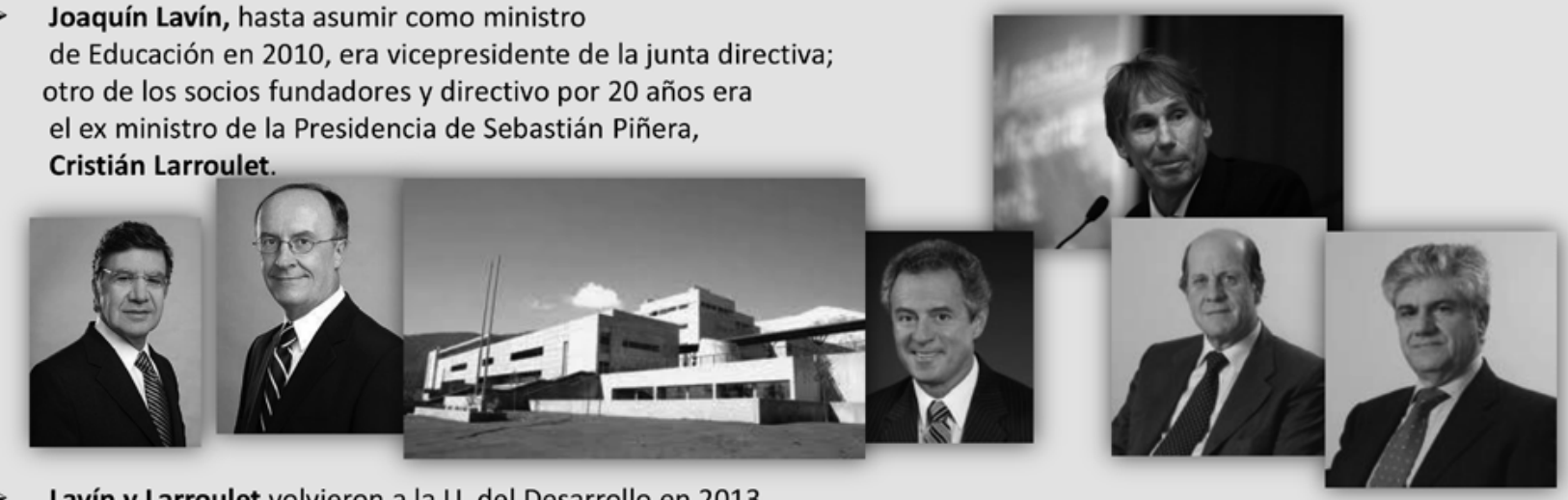

Lavín y Larroulet volvieron a la U. del Desarrollo en 2013.

$>$ Federico Valdés Lafontaine, ex presidente del club Azul-Azul y actual rector, es otro de los dueños de la Corporación y de la Inmobiliaria Ainavillo.

$>$ El grupo Penta, que tiene bancos, empresas aseguradoras e inmobiliarias, comparte la propiedad de la UDD. Sus máximas figuras, Carlos Alberto Délano y Carlos Eugenio Lavín, son parte del directorio.

$>$ La sede de San Carlos de Apoquindo la construyó Penta. Délano es tío del diputado y presidente de la UDI Eugenio Silva Méndez.

> En 2013 la UDD tenía 16.980 alumnos. 


\section{La universidad de los Ribera}

$>$ El ex ministro de Justicia de Piñera Teodoro Ribera Neumann está estrechamente ligado a las universidades privadas.

$>$ La U. Autónoma pertenece a su familia.

$>$ Su padre, Teodoro Ribera Beneit, preside la junta directiva; su hermano Jaime Ribera Neumann es el secretario general. Y el ex ministro era rector

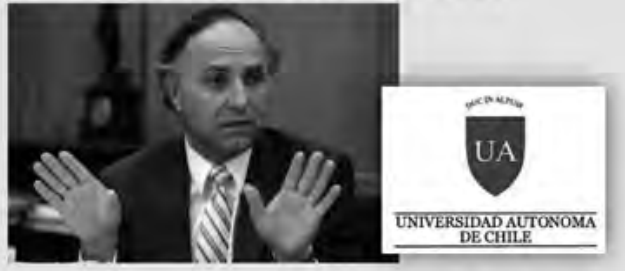
y principal motor hasta entrar al gabinete en marzo de 2010.

$>$ Contaban 27.132 alumnos en 2013.

$>$ Son dueños del Instituto Incacea $y$ tienen un colegio en Temuco.

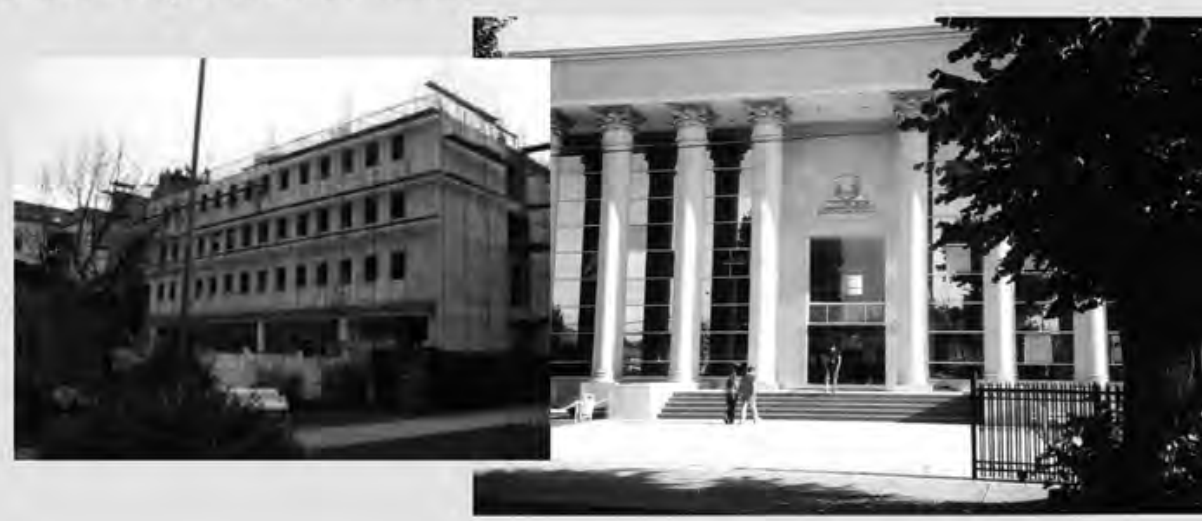




\section{Los nombres de la Mayor}

> Aunque no es de las doce investigadas por lucro, es interesante observar el directorio de la U. Históricamente ha estado un grupo de ex ministros de Augusto Pinochet, encabezados por Ricardo García Rodríguez, su histórico presidente.

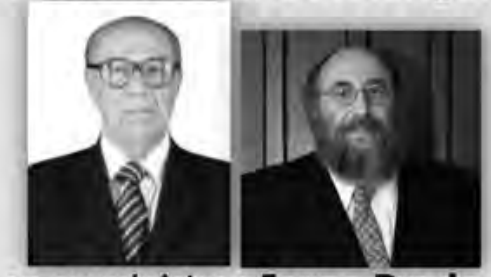

Los ex ministros Jorge Prado Aránguiz y Sergio Melnick

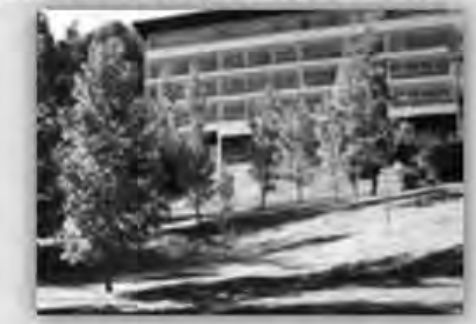

también son parte de su junta directiva, junto al abogado Mario Arnello
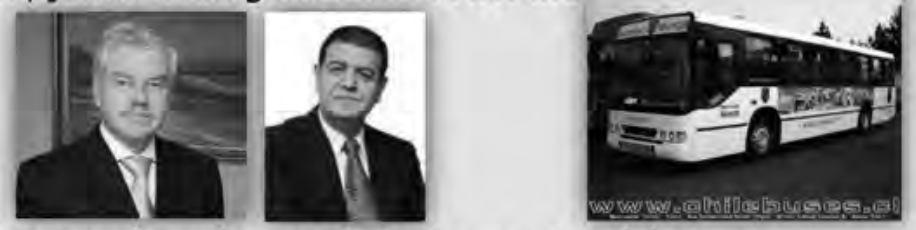

Su rector es Rubén Covarrubias, quien encabeza los movimientos en pro del apoyo estatal a las privadas. El vicerrector académico y de aseguramiento de calidad es René Salamé, último ministro de Educación de Pinochet que firmó la LOCE en marzo de 1990.

> Tenía 19.595 matriculados en 2013. 


\section{Pollos, cerdos y universidad}

En la región de Valparaíso está la Universidad de Aconcagua

La compró en 2008 Gonzalo Vial Concha.

Es hijo del empresario de pollos y cerdos Gonzalo Vial Vial, principal accionista de graneles de Chile, criador de caballos y aficionado al rodeo.

Los Vial son dueños de Agrosuper, Superpollo y la Crianza.

Además de las sucursales que la UAC tenía en La Ligua, San Felipe, Limache, Viña del Mar, Gonzalo Vial mantuvo su sede de Rancagua y en los últimos años ha abierto en más de 20 ciudades del país. 
7. UNIVERSIDAD DE CHILE

\section{En plena batalla...}

Al dar una mirada a las cifras y a los rostros de quienes están detrás de este negocio se puede advertir que la batalla por la educación superior recién empieza.

Los "guardianes del lucro" defienden y defenderán a brazo partido sus intereses.

Para cambiar las cosas es necesario realizar reformas estructurales a un sistema que de perpetuarse seguirá agudizando los innumerables problemas que actualmente se advierten en el país.

Es mucho lo que hay que hacer para generar los cambios. Pero hay que partir cuanto antes. Y está claro que el Estado y sus universidades tendrán que jugar un rol muy diferente al de los últimos 30 años. 